\title{
Evaluation of the Anti-ulcer Effect of Extra Virgin Avocado (Persea americana) Oil in Rats
}

\author{
Samuel James Offor, Adedayo Adedoyin Tologbonse, Sifon Obong John Akpan, \\ Victor Udo Anah, and Enobong Anietie Edward
}

\section{ABSTRACT}

Peptic ulcer disease is a gastrointestinal disorder of high mortality and morbidity. Therapy of this disease condition with conventional drugs presents therapeutic challenge due to incidents of unwanted side effects, and the high cost of these medications. The use of products from natural sources will provide useful alternatives due to their minimal side effects, being inexpensive, and readily available, especially in resource-challenged nations of the continent of Africa and other developing economies. Oils derived from plants are increasingly being used in management of several disease conditions. This study aims at evaluating the antiulcer activity of extra virgin avocado oil in rodents using ethanol-induced, and indomethacininduced ulcer models. Test group was given extra virgin avocado oil $(1 \mathrm{ml}$ per $250 \mathrm{~g}$ weight) for 7 days before induction of ulcer. Positive controls received omeprazole $30 \mathrm{mg} / \mathrm{kg}$, while negative control animals were given distilled water $(10 \mathrm{ml} / \mathbf{k g})$ for 7 days respectively, before induction of ulcer. The stomachs were excised, and their histopathological examinations carried out. Avocado oil significantly reduced the ulcer index in both models when compared to the negative control group, and histopathological findings corroborate that the oil ameliorates ulcerations in both models. The present study has demonstrated that extra virgin avocado oil possesses significant antiulcer activity.

Keywords: Avocado oil, extra-virgin, peptic ulcer disease, ulcer index.
Published Online: January 3, 2022

ISSN: $2795-8035$

DOI : $10.24018 /$ pharma.2022.2.1.15

\section{S. J. Offor*}

Department of Pharmacology and Toxicology, Faculty of Pharmacy, University of Uyo, Nigeria.

(e-mail: samueloffor@uniuyo.edu.ng) A. A. Tologbonse

Department of Pharmacology and Toxicology, Faculty of Pharmacy, University of Uyo, Nigeria.

(e-mail:

adeyotologbonse@uniuyo.edu.ng)

S. O. J. Akpan

Department of Pharmacology and

Toxicology, Faculty of Pharmacy, University of Uyo, Nigeria.

(e-mail: syphonesus@gmail.com)

V. U. Anah

Department of Pharmaceutical and Medicinal Chemistry, Faculty of Pharmacy, University of Uyo, Nigeria.

(e-mail: victoranah70@gmail.com)

E. A. Edward

Department of Pharmacology and

Toxicology, Faculty of Pharmacy, University of Uyo, Nigeria.

(e-mail: enyedward37@gmail.com)

*Corresponding Author

\section{INTRODUCTION}

Peptic ulcer disease (PUD) is a disease of the gastrointestinal tract, which comprises both gastric and duodenal ulcers. It is hallmarked by imbalances between offensive (gastric acid, pepsin, and Helicobacter pylori) and defensive (prostaglandins, bicarbonate ions, mucin, growth factors, and nitric oxide) factors [1]-[3]. Other causes of peptic ulcer disease include long term and high dose of drugs such as non-steroidal anti-inflammatory drugs (NSAIDs), smoking, stress, alcohol consumption, age-related decline in prostaglandin levels, and diseases such as Zollinger-Ellison syndrome [4], [5]. Peptic ulcer disease is the most common gastrointestinal disorder with significant mortality and morbidity globally [6]. Synthetic drugs such as proton pump inhibitors, antacids (aluminium hydroxide and magnesium trisilicate), histamine- $\mathrm{H}_{2}$ - receptor blockers (cimetidine and ranitidine), proton pump inhibitors (omeprazole and lansoprazole), cytoprotective agents (sucralfate and the prostaglandin analogue misoprostol), muscarinic antagonists (pirenzepine), and antimicrobial agents (amoxicillin and clarithromycin) are commonly used for treatment of peptic ulcer disease [7], [8]. However, these drugs have numerous side effects such as diarrhoea, headache, constipation, arrhythmia, hypomagnesemia, hypersensitivity, impotence and gynecomastia [9], [10]. Additionally, some of these drugs are expensive [11]. Herbal products are considered better alternatives as they have fewer side effects and better compatibility with the human body [12].

Oils obtained from plants are gaining wide popularity for their therapeutic potentials [13]. Some oils reported to be effective for treatment of peptic ulcer disease include virgin coconut oil [14], olive oil [15], ginger, clove, castor oils [16], and basil oil [17]. Avocado (Persea americana) is a fruit that is native to Central America. It is grown mainly in warm 
temperate and subtropical climates throughout the world. Hence, climate and country of origin can affect the fruit quality and therefore, the oil [18]. Extra-virgin avocado oil which is viscous, dark green in colour (due to chlorophylls and carotenoids contents), with a mild taste is obtained from the avocado fruit mostly by cold pressing, and without undergoing alterations in its nature by the addition of chemicals or subsequent processing [19]. Internationally, there are no defined parameters for avocado oil, and the values commonly used are those recommended for olive oil [18]. The quality standard for olive oil is documented in the Codex Alimentarius and the International Olive Oil Council [20]. Avocado oil was classified based on the extraction method and fruit quality by Woolfe and co-workers [21] as "Extra virgin," which is that produced from high-quality fruit, extracted only with mechanical methods at temperature below $50{ }^{\circ} \mathrm{C}$ and without the use of chemical solvents. "Virgin" avocado oil, is produced using lower quality fruits i.e., having small areas of rot and physical alterations, extracted mechanically at temperature below $50^{\circ} \mathrm{C}$, and with no added chemical solvents. The third class is "Pure" avocado oil whose fruit quality is not important. It is bleached, deodorized, and contains natural fruits or herbs flavour. The fourth is "Mixed" avocado oil which combines avocado oil with olive, macadamia, and other oils [18], [21]. The major producers of avocado oil in the world are Mexico, New Zealand, the United States, South Africa, and Chile [22].

Avocado oil has gained wide application in human nutrition, food industry, and cosmetics. The lipid content which consists mainly of monounsaturated fatty acids, has cardiovascular system benefits and anti-inflammatory potentials [18], [23]. Avocado oil contains more than $60 \%$ of monounsaturated fatty acids, a characteristic similar to that of olive oil, hazelnut, and macadamia nut. When compared with olive oil, avocado oil possesses a higher proportion of saturated fatty acids (16.4\%), mostly palmitic acid (15.7\%), a lower proportion of monounsaturated fatty acids $(67.8 \%)$, most of which is oleic acid (60.3\%), and a higher proportion of polyunsaturated fatty acids $(15.2 \%)$, most of which is linoleic acid (13.7\%) [24]. Avocado oil has been reported as having a higher polyunsaturated fatty acid/saturated fatty acid, and higher omega-6/omega-3 ratios than olive oil [25]. The presence of bioactive compounds such as tocopherols, tocotrienols, phytosterols, carotenoids, and polyphenols in avocado oil makes it of particular interest for research, targeted at the prevention and management of several disease conditions [18]. This study aims at the evaluation of antiulcer activity of Avocado fruit (Persia americana) oil using rodent models.

\section{MAterials AND METHODS}

\section{A. Preparation of Extra Virgin Avocado Oil}

Ten (10) mature, high-quality avocado fruits were bought from Uyo market, in Uyo Local Government Area of Akwa Ibom State, Nigeria. They were washed and kept until soft. The pulp was removed, mashed and spread on a large surface open container kept under room temperature. During this period, the pulpy mash was turned occasionally for faster drying. After about 4 days, droplets of the oil were seen on the surface (this shows its ready for extraction). The oil was squeezed from the paste using sieve cloth and then filtered to remove unwanted particles.

\section{B. Experimental Animals}

A total of 36 rats of both sexes, weighing (128-221 g) were obtained from the animal house of the Department of Pharmacology and Toxicology, Faculty of Pharmacy, University of Uyo. They were maintained on standard animal pellets and water ad libitum, housed in cages to acclimatize to the animal house, and maintained under standard conditions $\left(25-28^{\circ} \mathrm{C}\right)$ with $12 \mathrm{~h}$ dark/12h light cycles.

\section{Experimental Design}

The experimental rats were divided into three groups consisting of six rats per group. Rats of each group were orally pre-treated as follows:

Group 1 (Negative control): Given distilled water $(10 \mathrm{ml} / \mathrm{kg})$ for 7 days

Group 2 (Positive control): Given Omeprazole (30mg/kg) for7 days

Group 3 (Treatment group): Given Extra Virgin Avocado oil ( $1 \mathrm{ml}$ per $250 \mathrm{~g}$ body weight) for 7 days [26]. Animals were fasted for 24 hours into the $8^{\text {th }}$ day before the ulcer induction. Ethanol and Indomethacin models were used.

\section{Ethanol-Induced Ulcer Model}

Rats in each group were pre-treated for 7 days and fasted for $24 \mathrm{~h}$ into the $8^{\text {th }}$ day. On the eighth day, ulcer was induced through the administration of ethanol $(2 \mathrm{ml} / \mathrm{kg}) 1$ hour after administration of distilled water (group 1), omeprazole (group 2) and avocado oil (group 3), respectively. The animals were kept further for 4 hours for the ethanol to take effect. After the 4 hours, animals were euthanized by cervical dislocation under chloroform anaesthesia. The stomachs were excised and gently rinsed with normal saline, then inflated and with $1 \%$ formalin solution $(10 \mathrm{ml})$, and immersed in the same solution to fix the outer layer of the stomach [1], [27]. After about 10 minutes, each stomach was opened along the greater curvature, rinsed with normal saline to remove gastric contents, and examined by using a 10x magnifier lens to assess the formation of ulcers, then scored by using the Kulkarni method $(0=$ no ulcer, $0.5=$ red coloration, $1=$ spot ulcers, $2=$ deep ulcers, and $3=$ perforations) [28]. This procedure was performed by an expert in identification of ulcer types.

Ulcer index and percentage of ulcer inhibition were determined as follows:

$$
\text { Ulcer index }(\mathrm{UI})=\mathrm{U}_{\mathrm{N}}+\mathrm{U}_{\mathrm{S}}+\mathrm{UP}_{\mathrm{P}} \times 10^{-1}
$$

where $\mathrm{U}_{\mathrm{N}}=$ average number of ulcers per animal, $\mathrm{U}_{\mathrm{S}}=$ average of severity score, and $U_{P}=$ percentage of animals with ulcers.

$$
\text { Ulcer inhibition }(\%)=\frac{(U I \text { control }-U I \text { test })}{U I \text { control }} \times 100
$$

\section{E. Indomethacin-Induced Ulcer Model}

Rats in each group were pre-treated for 7 days and fasted for $24 \mathrm{~h}$ into the $8^{\text {th }}$ day. On the eighth day, ulcer was induced 
according to the method of Nwafor and co-workers with modifications [29] via the administration of indomethacin $(100 \mathrm{mg} / \mathrm{kg}) 1$ hour after administration of distilled water, indomethacin and avocado oil respectively. The animals were kept further for 4 hours for the indomethacin to take effect. After the 4 hours, the animals were euthanized by cervical dislocation under chloroform anaesthesia for macroscopical examination carried out with a hand lens and scored for the presence of lesions.

\section{F. Histopathology}

The stomach tissues which were preserved in $10 \%$ formalin pending histopathological studies were dehydrated serially through progressive concentrations of alcohol and cleared using xylene. After clearing, the tissues were embedded in paraffin wax and thin sections of about $5 \mu \mathrm{m}$ were made using the microtome. Each section was mounted on a clean glass slide and stained with Haematoxylin and Eosin. Later, a mounting medium (Canada balsam) was dropped on each tissue section and a cover slip placed on it and allowed to dry [30]. They were examined with a light microscope, and photomicrographs were captured using a Moticam Images plus 2.0 (Motic China Group Ltd.) digital Camera attached to the microscope.

\section{G. Ethical Issues}

The procedures were performed according to the guidelines on the use of animals and approved by the Institutional Animal Ethical Committee of the Faculty of Pharmacy, University of Uyo, Nigeria (Ethical Approval No: FPharm/EC/010).

\section{H. Statistical Analysis}

Results were expressed as mean \pm standard error of mean (SEM). Statistical analysis was carried out using SPSS version 23 statistical software. Statistical significance was determined using one-way Analysis of Variance (ANOVA) followed by Tukey's post hoc test. Values of $p<0.05$ were considered to be significant.

\section{RESUltS AND DisCUSSIONS}

\section{A. Effect of Persia Americana Oil on Ethanol-Induced Ulceration in Rats}

The effect of avocado oil on ethanol-induced gastric ulceration is as shown in Table I. Avocado oil pre-treated group significantly $(\mathrm{p}<0.05)$ prevented ulcer formation compared to that of negative control. The standard drug, omeprazole also caused reduction in ulcer index compared to the negative control but the variation is not statistically significant $(p>0.05)$. In addition, avocado oil showed better protection against ulcer with a higher percentage inhibition of $39.2 \%$ when compared to that of the standard drug, omeprazole with $17.5 \%$ ulcer inhibition. Induction of ulcer by ethanol is widely used in antiulcer animal model. Ethanol metabolism in the body releases superoxide anion, and hydroperoxyl free radicals, which are known to be part of the mechanisms of acute and chronic ulceration of the gastric mucosa [31].
TABLE I: EFFECT OF VIRGIN AVOCADO OIL ON ETHANOL-INDUCED ULCERATION IN RATS

\begin{tabular}{cccc}
\hline \hline Group & Treatment & Ulcer Index & $\begin{array}{c}\text { Percentage } \\
\text { Inhibition }\end{array}$ \\
\hline \hline $\begin{array}{c}\text { Normal } \\
\text { Control }\end{array}$ & $\begin{array}{c}\text { Distilled Water- } \\
10 \mathrm{ml} / \mathrm{kg} \\
\text { Positive }\end{array}$ & $3.83 \pm 0.31$ & - \\
Omeprazole- & $3.16 \pm 0.31$ & 17.5 \\
Avocado Oil & $\begin{array}{c}30 \mathrm{mg} / \mathrm{kg} \\
\text { ml per } 250 \mathrm{~g}\end{array}$ & $2.33 \pm 0.42^{\mathrm{a}}$ & 39.2 \\
\hline
\end{tabular}

Values are expressed as mean \pm SEM. Significant at ${ }^{\mathrm{a}} \mathrm{p}<0.05$ when compared to control $(\mathrm{n}=6)$.

\section{B. Effect of Persia Americana Oil on Indomethacin- Induced Ulceration in Rats}

The effect of Avocado oil on indomethacin-induced gastric ulceration is as shown in Table II. Rats pre-treated with Avocado oil showed significant $(\mathrm{p}<0.05)$ reduction in ulcer index compared to those in the normal and control groups, and have percentage ulcer inhibition of 38. However, this anti-ulcer potential of avocado oil was lower than that of the standard drug, omeprazole which apart from significantly $(\mathrm{p}<0.05)$ reducing the ulcer index relative to the control, also has a higher percentage inhibition (59\%). Indomethacin has been shown to exhibit greater gastric damage in rodents when compared to other NSAIDs [31]. Hence, it has become preferrable for inducing ulcers [32]. It causes damage to stomach tissue by increasing gastric acid, pepsin activity, and enhances lipid peroxidation and oxidative stress via production of free radicals in mucus [33].

Significant $(\mathrm{p}<0.05)$ reduction in ulcer index compared to those in the normal and control groups and have percentage ulcer inhibition of 38 . However, this anti-ulcer potential of avocado oil was lower than that of the standard drug, omeprazole which apart from significantly $(\mathrm{p}<0.05)$ reducing the ulcer index relative to the control, also has a higher percentage inhibition (59\%). Indomethacin has been shown to exhibit greater gastric damage in rodents when compared to other NSAIDs [32]. Hence, it has become preferrable for inducing ulcers [33]. It causes damage to stomach tissue by increasing gastric acid, pepsin activity, and also enhances lipid peroxidation and oxidative stress via production of free radicals in mucus [34].

\section{Histopathology of the Stomach}

TABLE II: EFFECT OF VIRGIN AVOCADO OIL ON INDOMETHACIN-INDUCED ULCERATION IN RATS

\begin{tabular}{cccc}
\hline \hline Group & Treatment & Ulcer Index & $\begin{array}{c}\text { Percentage } \\
\text { Inhibition }\end{array}$ \\
\hline \hline $\begin{array}{c}\text { Normal } \\
\text { Control }\end{array}$ & $\begin{array}{c}\text { Distilled } \\
\text { Water- } 10 \\
\mathrm{ml} / \mathrm{kg}\end{array}$ & $8.33 \pm 0.35$ & - \\
$\begin{array}{c}\text { Positive } \\
\text { Control }\end{array}$ & $\begin{array}{c}\text { Omeprazole- } \\
30 \mathrm{mg} / \mathrm{kg} \\
1 \mathrm{ml} \mathrm{per} 250 \mathrm{~g} \\
\text { body weight }\end{array}$ & $3.41 \pm 0.19^{\mathrm{a}}$ & 59.0 \\
Avocado Oil & $5.16 \pm 0.16^{\mathrm{a}}$ & 38.0 \\
\hline \hline
\end{tabular}

Values are expressed as mean \pm SEM. Significant at ${ }^{a} \mathrm{p}<0.05$ when compared to control $(n=6)$.

The results of the histopathological studies on the inner lining of the excised stomachs of the experimental animals, are shown in Fig. 1. A-C displays a representative image of each of the groups of the alcohol-induced ulcer model, while D-F shows the results of the indomethacin-induced ulcer model. 
Results from observation of stomach of the various groups established severe ulceration induced by both alcohol and indomethacin (control groups). However, avocado treatment tends to ameliorate the ulcerations in both models, especially in the alcohol-induced model when compared to the control group. Indomethacin tends to be less gastro-toxic as compared to alcohol. Omeprazole, the standard drug also attenuates the toxicity induced by both alcohol and indomethacin, especially in the indomethacin model when compared to the negative control group. The antiulcer potential of avocado oil may be attributable to the bioactive constituents present in avocado fruit. Reference [35] reported the presence of alkaloids, saponins, unsaturated steroids and triterpenoids (Leucoanthocyanins), fats and oils in the ethanolic extract of $P$. americana. Tocopherols have also been identified in the avocado acetone extract [36]. The oil retains most of the bioactive substances and carotenoids present in the fruit [37].

\section{CONCLUSION}

The present study showed that extra virgin avocado oil has significant anti-ulcer activity. However, further research work should be carried out to elucidate the exact mechanism(s) of action. Since the oil was administered in its natural form without any adulteration, it could be used as a nutritional recipe for ulcer patients (for example, as salad dressing, for stir frying etc.), and as potential candidate for preparation of natural remedies used in mitigating peptic ulcer disease in humans.

\section{CONFLICT OF INTEREST}

Authors declare that they do not have any conflict of interest.
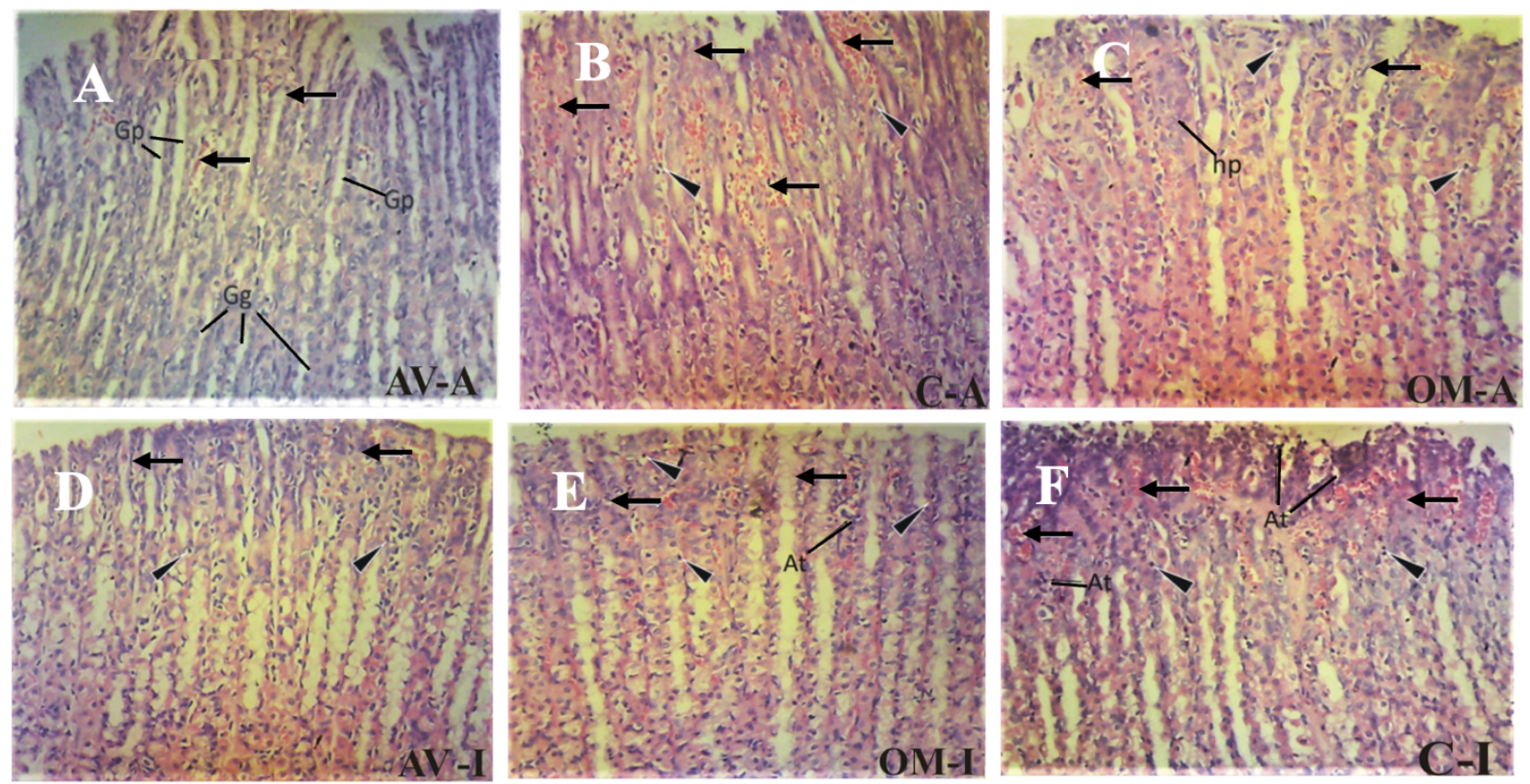

Fig. 1. (A)-Histological photomicrograph of the Avocado treated rat stomach alteration induced with alcohol (AV-A, group 3) stained with H\&E techniques showing an abnormal digestive tissue with the gastric pits having wide area of hemorrhagic blood vessel (arrow), gastric glands (Gg) and infiltrating inflammatory cells within the stomach endometrium at magnification (x100). Inference: Moderately ulcerated; (B)-Photomicrograph of the longitudinal section of Control rat stomach alteration induced with alcohol (C-A) showing the histo-structure of an abnormal digestive tissue with the gastric pits having wide areas of hemorrhagic blood vessel (arrow), degenerating glandular epithelial cells (hp), wide infiltration of inflammatory cells (arrowhead) within the stomach endometrium and eroding endothelial lining cells at magnification (x100). Inference; severely ulcerated; (C)- Photomicrograph of the longitudinal section of the Omeprazole treated rat stomach alteration induced with Alcohol (OM-A) showing the histo-architecture of an abnormal digestive tissue with the gastric pits having mild area of hemorrhagic blood vessel (arrow), hyperplasic glandular epithelial cells (hp) and few infiltrating inflammatory cells (arrowhead) within the stomach endometrium at magnification (x100). Inference: Mildly ulcerated. (D)-Photomicrograph of the longitudinal section of the Avocado treated rat stomach alteration induced with Indomethacin (AV-I) showing the histo-architecture of an abnormal digestive tissue with the gastric pits having scanty areas of hemorrhagic blood vessels (arrow) and infiltrating inflammatory cells within the stomach endometrium at magnification (x100). Inference: Mildly ulcerated; (E)- Photomicrograph of the longitudinal section of the Omeprazole treated rat stomach alteration induced with Indomethacin (OM-I) showing the histo-architecture of an abnormal digestive tissue with the gastric pits having wide area of hemorrhagic blood vessels (arrow), atrophying glandular epithelial cells (At) and infiltrating inflammatory (arrowhead) cells within the stomach endometrium at magnification (x100).

Inference: Moderately ulcerated; (F)-Photomicrograph of the longitudinal section of the negative control rat stomach alteration induced with indomethacin (C-I) showing the histo-structure of an abnormal digestive tissue with the gastric pits having wide areas of hemorrhagic blood vessel (arrow), degenerating glandular epithelial cells, wide infiltration of inflammatory cells (arrowhead) within the stomach endometrium and eroding endothelial lining cells at magnification (x100). Inference: Severely ulcerated.

\section{REFERENCES}

[1] Mekonnen AN, Atnafie SA, Wahab Atta MA. Evaluation of antiulcer activity of $80 \%$ methanol extract and solvent fractions of the root of Croton macrostachyus Hocsht: Ex Del. (Euphorbiaceae) in rodents.
Evidence-Based Complementary and Alternative Medicine (Hindawi) 2020; 2020: 1-11.

[2] Ayantunde AA. Current opinions in bleeding peptic ulcer disease Journal of Gastrointestinal \& Digestive System. 2014; 4: 172.

[3] Byrge N, Barton RG, Enniss TM, Nirula R. Laparoscopic versus open repair of perforated gastroduodenal ulcer: a National surgical quality improvement program analysis. The American Journal of Surgery. 2013; 206(6): 957-963. 
[4] Bashir A, Hazarika I, Jaikumar S, Akila KP, Shefeer KA. Anti - ulcer activity of polyherbal formulation - RO12 on experimentally induced ulcer in rats. International Journal of Phytopharmacology. 2014; 5(6): 406-410.

[5] Stewart DJ, Ackroyd R. Peptic ulcers and their complications. Surgery. 2011; 29(11): 568-574.

[6] Daniel VT, Wiseman JT, Flahive J, Santry HP. Predictors of mortality in the elderly after open repair for perforated peptic ulcer disease. Journal of Surgical Research. 2017; 215: 108-113.

[7] Sabiu S, Garuba T, Sunmonu T, Ajani E, Sulyman A, Nurain I, Balogun A. Indomethacin-induced gastric ulceration in rats: protective roles of Spondias mombin and Ficus exasperate. Toxicological Reports. 2015; 2: 261-267.

[8] Oliveira F, Andrade LN, Vieira de Sousa EB, Pergentino de Sousa D. Anti-Ulcer Activity of Essential Oil Constituents. Molecules. 2014; 19: 5717-5747.

[9] Nyam KL, Tang JLK, Long K. Anti-ulcer activity of Hibiscus cannabinus and Hibiscus sabdariffa seeds in ulcer-induced rats. International Food Research Journal. 2016; 23(3): 1164-1172.

[10] Oliveira FD, Andrade LN, Vieira de Sousa EB, Pergentino de Sousa D. Anti-ulcer activity of essential oil constituents. Molecules. 2014; 19: 5718-5749.

[11] Klein LC, Gandolfi RB, Santin JR, Lemos M, Cechinel-Filho V, de Andrade SF. Antiulcergenic activity of extract, fractions, and some compounds obtained from Polygala cyparissias St. Hillaire \& Moquin (Poligalaceae) Naunym Schmiedebergs. Arch Pharmacol. 2010; 381: 121-126.

[12] Parekh J, Jadeja D. Chanda S. Efficacy of aqueous and methanol extracts of some medicinal plants for potential antibacterial activity. Turkish Journal of Biology. 2005; 29: 203-210.

[13] Meng J, Chen T, Zhao Y, Lu S, Yu H, Chang Y, et al. Study of the mechanism of anti-ulcer effects of virgin coconut oil on gastric ulcerinduced rat model. Archives of medical science: $A M S$. 2019; 15(5): 1329.

[14] Selverajah M, Zakaria ZA, Long K, Ahmad Z, Yaacob A, Somchit MN. Anti-ulcerogenic activity of virgin coconut oil contribute to the stomach health of humankind. Tang. 2016; 6: 8-12.

[15] Castro M, Romero C, de Castro A, Vargas J, Medina E, Millan R, et al. Assessment of Helicobacter pylori eradication by virgin olive oil. Helicobacter, 2012; 17(4): 305-315.

[16] El-Metwally EM. Evaluation of antiulcer activity of ginger, clove and castor oils against aspirin induced gastric ulcers in rats. World Applied Sciences Journal. 2014; 29(7): 815-824.

[17] Farghali HAMA, Ghozy SFAE, El-Mehiry HF. Study the Effect of Basil Oil as Herbal Treatment of Acetylsalicylate Induced Gastric Ulcer in Experimental Rat Model. Global Veterinaria. 2014; 12(4): 431-448.

[18] Flores M, Saravia C, Vergara CE, Avila F, Valdes H, Ortiz-Viedma J. Avocado Oil: Characteristics, Properties, and Applications. Molecules. 2019; 24(11): 2172.

[19] Wang M, Yu P, Chittiboyina AG, Chen D, Zhao J, Avula B, e al. Characterization, quantification and quality assessment of avocado (Persea americana Mill.) oils. Molecules. 2020; 25(6): 1453.

[20] Di Stefano V, Avellone G, Bongiorno D, Indelicato S, Massenti R, Lo bianco R. Quantitative evaluation of the phenolic profile in fruits of six avocado (persea americana) cultivars by ultra-high-performance liquid chromatography-heated electrospray-mass spectrometry. Int. J. Food Prop. 2017; 20: 1302-1312.

[21] Woolf A, Wong M, Eyres L, McGhie T, Lund C, Olsson S, et al. Avocado oil. From cosmetic to culinary oil. In: Moreau R., KamalEldin A., editors. Gourmet and Health-Promoting Specialty Oils. AOCS Press; Urbana, IL, USA. 2009: 73-125.

[22] Berasategi I, Barriuso B, Ansorena D, Astiasarán I. Stability of avocado oil during heating: Comparative study to olive oil. Food Chem. 2012; 1: 439-446.

[23] Carvajal-Zarrabal O, Nolasco-Hipolito C, Aguilar-Uscanga M, MeloSantiesteban G, Hayward-Jones P, Barradas-Dermitz D. Avocado oil supplementation modifies cardiovascular risk profile markers in a rat model of sucrose-induced metabolic changes. Dis. Markers. 2014; 386-425.

[24] Dubois V, Breton S, Linder M, Fanni J, Parmentier M. Fatty acid profiles of 80 vegetable oils with regard to their nutritional potential. Eur. J. Lipid Sci. Technol. 2007; 109: 710-732.

[25] Berasategi I, Barriuso B, Ansorena D, Astiasarán I. Stability of avocado oil during heating: Comparative study to olive oil. Food Chem. 2012; 1: 439-446.

[26] Abozaid OAR, Aziza SAH, Moawed FSM, Kasseb, SG. Avocado oil attenuates Diethyl nitrosamine-induced hepatic carcinogenesis. Bahama Vertinary Medical Journal. 2018; 3(2): 344-353.
[27] Mizui T, Doteuchi M. Effect of polyamines on acidified ethanolinduced gastric lesions in rats. The Japanese Journal of Pharmacology. 1983; 33(5): 939-945.

[28] Kulkarni SK. HandBook of Experimental Pharmacology, Vallabh Prakashan. New Delhi, India, 3rd edition. 2002.

[29] Nwafor PA, Okwuasaba FK, Binda LG. Antidiarrheal and antiulcerogenic effects of methanolic extract of Asparagus pubescens root in rats. Journal of Ethnopharmacology. 2000; 72: 421-427.

[30] Nowacek JM. Fixation and tissue processing. Pathology Education Guide: Special Stains and $H \&$ E. 2nd ed. Dako North America, California, 141- 52

[31] Bora NS, Bairy PS, Salam A, Kakoti BB. Antidiabetic and antiulcerative potential of Garcinia lanceifolia Roxb. Bark. Future Journal of Pharmaceutical Sciences. 2020; 6: 85.

[32] Takeuchi K, Tanaka A, Hayashi Y, Yokota A. COX inhibition and NSAID-induced gastric damage - roles in various pathogenic events. Curr Top Med Chem. 2005; 5: 475-486.

[33] Dursun H, Bilici M, Albayrak F, Ozturk C, Saglam MB, Alp HH, et al. Antiulcer activity of fluvoxamine in rats and its effect on oxidant and antioxidant parameters in stomach tissue. BMC Gastroenterol. 2009; 9(1): $1-10$.

[34] Suleyman H, Albayrak A, Bilici M, Cadirci E, Halici Z. Different mechanisms in formation and prevention of indomethacin-induced gastric ulcers. Inflammation. 2010; 33(4): 224-234.

[35] Torres RC, Garbo AG, Walde RZML. Larvicidal activity of Persea americana Mill. against Aedes aegypti. Asian Pacific Journal of Tropical Medicine. 2014; 7S1, S167-S170.

[36] Corral-Aguayo RD, Yahia EM, Carrillo-Lopez A, Gonzalez-Aguilar G. Correlation between some nutritional components and the total antioxidant capacity measured with six different assays in eight horticultural crops. J Agric Food Chem. 2008; 56: 10498-10504.

[37] Ranade SS, Thiagarajan P. A review on Persea americana Mill. (Avocado)- Its fruit and oil. International Journal of PharmTech Research. 2015; 8(6): 72-77. 